Азиатско-Тихоокеанский регион: экономика, политика, право. 2021. Т. 24, № 4. С. 145-153. Pacific Rim: Economics, Politics, Law. 2021. V. 24, No 4. P. 145-153.

\title{
ПРАВО
}

Научная статья

УДК $343.3 / .7$

https://doi.org/10.24866/1813-3274/2021-4/145-153

\section{О КРИТЕРИЯХ ОБОСОБЛЕНИЯ ИНСТИТУТОВ ОСОБЕННОЙ ЧАСТИ УГОЛОВНОГО ПРАВА}

\section{Руслан Георгиевич Асланян}

Кубанский государственный университет, 350040, Россия, г. Краснодар, ул. Ставропольская, 149; aslanyanruslan@ mail.ru

Аннотация. В статье освещаются значимые вопросы систематизации институтов особенной части уголовного права, осуществляется поиск надёжного и объективного критерия, согласно которому в структуре отрасли возможно их обособление. Исследование доказывает, что объединение всего массива институтов уголовного права относятся либо к правовым общностям, обслуживающим категории общей части, либо к правовым общностям, регламентирующим ответственность за преступления различного вида, является методологически неверным. В связи с чем более плодотворной выглядит идея раздельного анализа институтов общей и особенной части уголовного права. Между тем, решение вопросов градации и систематизации институтов особенной части уголовного права с опорой на представления о предмете уголовно-правового регулирования либо с опорой на классификацию преступлений, является бесперспективным. Институты особенной части уголовного права могут быть представлены в качестве системы нормативных предписаний, сгруппированных на основе подлежащих уголовно-правовой охране и институционализированных в системе общественных отношений правовых благ и интересов.

Ключевые слова: особенная часть уголовного права, уголовно-правовой институт, классификация преступлений, объект уголовно-правовой охраны, интерес, благо, систематизация, нормативное предписание, общественные отношения, отрасль права, основание права, правопонимание, функции уголовного права, юридический факт.

(C) Асланян Р. Г., 2021 
Для цุитирования: Асланян Р. Г. О критериях обособления институтов особенной части уголовного права // Азиатско-Тихоокеанский регион: экономика, политика, право. 2021. Т. 24, № 4. С. 145-153. https://doi.org/10.24866/1813-3274/2021-4/145-153.

\title{
LAW
}

Original article

\section{ON THE CRITERIA FOR THE SEPARATION OF INSTITUTIONS OF A SPECIAL PART OF CRIMINAL LAW}

\author{
Ruslan G. Aslanyan \\ Kuban State University, Krasnodar, Russia; 350040, Russia, Krasnodar, 149, \\ Stavropolskaya St.; aslanyanruslan@mail.ru
}

Abstract. The article highlights significant issues of systematization of institutions of a special part of criminal law, searches for a reliable and objective criterion according to which their isolation is possible in the structure of the industry. The study proves that the unification of the entire array of criminal law institutions belong either to legal communities serving the categories of the general part, or to legal communities regulating responsibility for crimes of various types, is methodologically incorrect. In this connection, the idea of a separate analysis of the institutions of the general and special part of criminal law looks more fruitful. Meanwhile, the solution of issues of gradation and systematization of institutions of a special part of criminal law based on ideas about the subject of criminal law regulation or based on the classification of crimes is unpromising. Institutions of a special part of criminal law can be represented as a system of normative prescriptions grouped on the basis of legal goods and interests subject to criminal law protection and institutionalized in the system of public relations.

Keywords: special part of criminal law, criminal law institute, classification of crimes, object of criminal law protection, interest, benefit, systematization, normative prescription, public relations, branch of law, basis of law, legal thinking, functions of criminal law, legal fact.

For citing: Aslanyan R. G. On the criteria for the separation of institutions of a special part of criminal law // Pacific RIM: Economics, Politics, Law. 2021. V. 24, No 4. P. 145-153. https://doi.org/10.24866/1813-3274/2021-4/145-153.

Проблемы классификации и систематизации институтов особенной части уголовного права, несмотря на их высокое научно-прикладное значение, не получили в современной науке должного анализа, а требования строгой научной методологии их познания не получили должной реализации. Обзор теоретических источников по те- 
Асланян Р. Г. О критериях обособления институтов особенной части уголовного права

ме показывает, что в литературе в целом сложилось несколько основных подходов к решению вопроса о видах уголовно-правовых институтов и их системе.

Так, оригинальное видение системы уголовно-правовых институтов было предложено В. Д. Филимоновым, который проводит градацию институтов в зависимости от функциональных особенностей. Он указывает, что систему уголовного права образуют: a) институты, оказывающие непосредственное воздействие на регулируемые уголовным правом общественные отношения (к этой группе автор относит все институты особенной части, а также некоторые институты общей части, которые определяют круг лиц, подлежащих уголовной ответственности, объём и пределы этой ответственности); б) институты, не оказывающие непосредственного воздействия на регулируемые уголовным правом отношения, но обеспечивающие осуществление такого воздействия (регламентируют деятельность суда по возложению уголовной ответственности и её индивидуализации); в) институты, не входящие в две указанные категории правовых общностей, но являющиеся их составными частями (институт состава преступления, институт условного осуждения и некоторые другие) [9, с. 133-134].

При всей значимости функционального подхода к пониманию права и его строения, нельзя не заметить, что в этой концепции заложена существенная методологическая и логическая ошибка. Во-первых, не ясна грань между «воздействием» и «обеспечением воздействия». Если тот или иной институт уголовного права не участвует в уголовно-правовом воздействии (или регулировании), вряд ли есть основания к тому, чтобы в принципе считать его отраслевым институтом, учитывая общепризнанное понимание института как группы норм или предписаний, которые комплексно регулируют соответствующую группу правоотношений. Во-вторых, не вполне понятно место институтов третьей группы, которые, с одной стороны, не воздействуют на общественные отношения и не обеспечивают такого воздействия, но, с другой стороны, в то же самое время выступают частью двух предыдущих групп уголовно-правовых институтов.

Видимо, в силу этих причин концепция В. Д. Филимонова не получила широкой поддержки в науке, где большая часть специалистов решает вопросы градации и систематизации уголовно-правовых институтов с опорой на представления о предмете уголовно-правового регулирования и структуре законодательства. Однако и здесь нет единства научных позиций.

Ряд авторов все институты уголовного права делит на группы, ориентируясь при этом на основные категории общей части. Наиболее ярко этот подход сформулирован Т. Г. Понятовской, которая системообразующими категориями институционального строения отрасли уголовного права признаёт «преступление» и «наказание». Она пишет: «Коль скоро институты уголовного права служат воплощению в правовую действительность концептуально обусловленных правовых категорий преступления и наказания, то они, в связи с этим, могут быть классифицированы. 
Можно выделить институты, которые служат критериями оценки конкретных обстоятельств дела исходя из содержания и концептуального значения понятия преступления, и те, которые служат юридическому оформлению надлежащей наказуемости» [6, с. 151-152]. Не отличается принципиально позиция Н. Ф. Кузнецовой, которая к содержанию уголовного законодательства относит четыре института: «уголовный закон», «преступление», «наказание», «освобождение от уголовной ответственности и наказания», которые систематизированы в общей и особенной частях уголовного закона и делятся на более дробные институты [3, с. 3]. Близки к этому и рассуждения В. В. Мальцева, который классифицирует уголовно-правовые нормы по их принадлежности к «основным системам уголовного законодательства»: «уголовному закону», «преступлению» и «наказанию» [5, с. 252].

Представленные построения, с одной стороны, весьма убедительны. Всё в уголовном праве «вращается» вокруг преступления и наказания. Однако существенный повод для их критики даёт то обстоятельство, что в основу строения права как нормативной реальности авторы положили не нормативные, а доктринальные критерии. Это обстоятельство представляется нам серьёзной методологической ошибкой. Нормативные предписания особенной части уголовного права, представляя собой единый, логически неразрывный ряд суждений законодателя о преступности и наказуемости того или иного вида деяния, не могут быть, с одной стороны, всецело помещены в институты, «обслуживающие» категорию преступления либо наказания, а с другой стороны, не могут быть расчленены на составные элементы (диспозиции и санкции), с тем, чтобы каждый из этих элементов стал частью института преступления либо института наказания.

Ошибку иного рода допускают специалисты, которые предлагают вариант институционального строения отрасли уголовного права на основе понятия логической уголовно-правовой нормы. Будучи целостным правилом поведения граждан и государства в сфере уголовно-правовых отношений, такие нормы не могут быть дифференцированы на нормы общей и особенной части. Отталкиваясь от этой посылки, Ю. Е. Пудовочкин, например, систему институтов уголовного права представляет исключительно как систему охранительных институтов, каждый из которых образует практически все предписания общей части уголовного законодательства, а также предписания особенной части об ответственности за тот или иной вид преступлений, имеющих общий родовой объект [7, с. 85]. В основе институционального строения отрасли при таком решении оказывается структура особенной части уголовного права, в укрупненные элементы которой включаются все положения общей части. Критикуя этот подход, В. В. Мальцев совершенно справедливо, на наш взгляд, заметил, что, вопервых, логическая уголовно-правовая норма сама по себе при предложенном подходе гораздо ближе к понятию института, нежели собственно к норме права, а во-вторых, что ни одна норма и даже институт уголовного права не могут вмещать в себя фактически всё уголовное законодательство [5, с. 230-231]. К тому же, сводить всё многооб- 
Асланян Р. Г. О критериях обособления институтов особенной части уголовного права

разие уголовно-правовых институтов только и исключительно к одному виду - правоохранительных - принципиально не верно [2, с. 157].

Таким образом, попытки структурно-ориентированного исследования системы институтов уголовного права, основанные на ассоциаџиях всех их либо с категориями общей части, либо - отдельно - с нормами особенной части уголовного права, не приводят к положительному решению вопроса о видах и системе уголовно-правовых институтов.

С учётом этого обстоятельства становится понятной популярность теоретических построений, допускающих самостоятельный и дифференцированный анализ институтов общей и особенной части уголовного права.

Наиболее отчетливо идея раздельного анализа институтов общей и особенной части уголовного права была разработана Э. С. Тенчовым [8, с. 23-24], с подачи которого подсистема институтов особенной части уголовного права стала пониматься в науке в качестве институтов отдельных видов преступлений, обособленных на основе общности родового объекта посягательства. Так, уже в наши дни Н. А. Лопашенко указывает, что «институты особенной части уголовного права выделяют по главам УК РФ, в которых сосредоточены уголовно-правовые нормы, относящиеся к посягательствам на однородные объекты. <..> В основе уголовно-правового института, таким образом, лежит единый охраняемый уголовным правом достаточно крупный объект охраны - родовой или видовой». При этом, однако, Н. А. Лопашенко делает одно важное замечание: «...по отношению к Особенной части сам термин «институт уголовного права» употребляется довольно редко; чаще ведут речь о группах преступлений, посягающих на один и тот же объект» [4, с. 20].

В этом, как представляется, и состоит основная, исходная проблема учения об институтах особенной части уголовного права: признавая сам факт наличия таких институтов in abstracto, наука так и не приступила $\kappa$ их исследованию іп concreto, а сама идея изучения институтов особенной части уголовного права была трансформирована в идею исследования проблем классификации преступлений.

Действительно, классификация преступлений и система особенной части уголовного права - связанные феномены. Но вместе с тем, это феномень принципиально различные.

В связи с этим в рамках анализа особенной части уголовного права необходимо вести речь не столько о системе преступлений, сколько о системе уголовноправовых предписаний, в которых устанавливается ответственность за их совершение. Критерии и основания градации и систематизации преступлений и правовых предписаний - объективно различны. По этой причине всё, что касается собственно преступления как факта объективной реальности, не может быть «зеркально» использовано для систематизации предписаний особенной части уголовного права. 
Дело в том, что классификация преступлений может строиться исходя из самых различных оснований, и вопрос о том, какая из этих классификаций должна быть положена в основу строения особенной части уголовного права, не является предрешённым. Стоит также напомнить, например, что в дореволюционной правовой теории система особенной части уголовного права строилась исходя из градации преступлений на три группы - против личности, против общества и против государства, а в современном уголовном законе Франции в основу группировки предписаний об ответственности за преступления положен не только объект охраны, но и форма вины, в связи с чем выделяются, в частности, умышленные и неумышленные посягательства на жизнь человека и др. Гипотетически не исключено построение системы особенной части на основе самых различных классификаций преступных деяний, но далеко не всякая такая классификация будет отражать систему институтов особенной части уголовного права. Ибо в классификации преступлений выбор критерия градаџии преступных деяний обусловлен познавательными интересами субъекта классификации, и в этом отнотении классификация всегда в известной степени субъективна, тогда как система институтов особенной части уголовного права есть феномен объективный и до известных пределов не зависящий от личности субъекта познания. Мы выявляем, открываем эту систему, но мы не в состоянии её создавать или перекраивать, руководствуясь теми или иными идеями относительно градации преступлений.

Объективным социальным основанием права, в том числе и его институционального строения, выступает система общественных отношений, которые правом регулируются. По этой причине многие специалисты, как уже было отмечено, критерий выделения институтов права связывают с организацией регулирования тех или иных видов или участков правовых отношений. Однако этот подход, справедливый для регулятивных отраслей права (тем более имеющих комплексный предмет), не в полной мере учитывает социальные основания уголовного права, развивающегося, в первую очередь, как охранительная отрасль. Современные уголовно-правовые предписания особенной части «генетически» восходят к охранительным положениям регулятивных отраслей права и обусловлены не столько предметом собственно уголовно-правового регулирования (отношениями, которые возникают в связи с фактом совершения преступления), сколько предметом уголовно-правовой охраны (отношениями, которые существуют до и вне момента совершения преступления и в уголовно-правовой защите которых общество жизненно заинтересовано).

В контексте исследования институтов особенной части уголовного права принципиально важно подчеркнуть, что, вопреки распространенному мнению, в основе их систематизации должен лежать не объект преступления - элемент реальности, который терпит ущерб от посягательства виновного лица, а объект уголовно-правовой охраны. Именно объект уголовно-правовой охраны выступает соии- 
Асланян Р. Г. О критериях обособления институтов особенной части уголовного права

альным основанием формирования институтов, выделения их в структуре особенной части уголовного права и систематизации.

Во-первых, объект уголовно-правовой охраны должен мыслиться как объективный феномен. Сам по себе он не зависит ни от направленности умысла преступника (в отличие от объекта преступления), ни от решения законодателя взять те или иные отношения под охрану. Это объективно сложившиеся и объективно необходимые для существования и развития общества отношения. В связи с этим, объект уголовноправовой охраны может рассматриваться не только в данностном отношении, как то, что уже охраняется правом, но и в ценностно-прогностическом отношении, как то, что может и должно подлежать охране, то есть как основа для развития уголовного права и появления в его структуре новых правовых предписаний и институтов.

Во-вторых, объект уголовно-правовой охраны именно в силу своей объективности является частью социально-нормативной системы общества, укоренен в обществе, а потому может выступать в качестве критерия оценки соответствия системы особенной части уголовного права социальным реалиям и потребностям, социальной обусловленности уголовного законодательства.

В-третьих, возможные различия в объективной системе объектов уголовноправовой охраны и субъективной, уголовно-политически мотивированной системе объектов, поставленных законодателем под охрану, позволяют выявить несовпадения в должной системе институтов уголовного права и системе уголовного законодательства, выявить так называемые «мёртвые нормы» и «мёртвые институты» [1].

В-четвёртых, объект уголовно-правовой охраны всегда соотнесён с социальными и социально-правовыми институтами. Между системой этих институтов и системой объектов уголовно-правовой охраны имеется прямая корреляция, а потому наличие системных связей между социальными институтами позволяет констатировать наличие таковых между объектами уголовно-правовой охраны и в целом рассматривать обусловленные этими объектами институты особенной части уголовного права в качестве системы.

Таким образом, институть особенной части уголовного права могут быть представлены в качестве системы нормативных предписаний, сгруппированных на основе подлежащчх уголовно-правовой охране и институционализированньх в системе общественных отношений правовых благ и интересов. Только в этом случае система особенной части уголовного права может быть адекватно, во-первых, «вписана» в нормативную структуру общества, а во-вторых, соотнесена с функциями уголовного права.

Институт особенной части уголовного права, при таком подходе, с одной стороны, обеспечивает целостную, всестороннюю охрану некоего объекта, реализуя охранительную функцию уголовного права, и одновременно, с другой стороны, обеспечивает регулирующие воздействие на эти охраняемые общественные отношения. Сказанное не означает, что уголовно-правовые институты не выполняют 
непосредственно регулятивной функции. Отрицать наличие у уголовного права регулятивной функции недопустимо. Однако отношения, составляющие предмет уголовно-правового регулирования (то есть те отношения, которые возникают между государством и лицом, совершившим преступление, с момента совершения преступления), не могут быть дифференцированы на группы или виды в зависимости от того, какими институтами особенной части уголовного права они регулируются. Урегулированные различными институтами особенной части уголовного права, эти отношения не являются различными правоотношениями, и потому сами по себе не составляют критериев систематизации уголовно-правовых институтов. Предмет, метод, режим регулирования уголовно-правовых отношений в рамках различных институтов особенной части уголовного права являются идентичными. Соответственно, сами эти отношения, предписания, которые их регулируют, юридические факты, в связи с которыми они возникают, иными словами - любые юридические характеристики отрасли уголовного права не могут выступать основой формирования и систематизации институтов особенной части уголовного права.

\section{Список источников}

1. Бабаев, М. М. «Мёртвые» нормы в Уголовном кодексе: проблемы и решения / М. М. Бабаев, Ю. Е. Пудовочкин // Уголовное право. - 2010. - № 6. - С. 4-10.

2. Жук, М. С. Институты российского уголовного права: понятие, система и перспективы развития: дис.. ... д-ра юрид. наук / М. С. Жук. - Краснодар, 2013. - 380 с.

3. Курс уголовного права : в 5-ти т. Т. 1 : Учение о преступлении / под ред. Н. Ф. Кузнецовой, И. М. Тяжковой. - Москва : Зерцало-М, 2002. - 624 с.

4. Лопашенко, Н. А. Введение в уголовное право : учебное пособие / Н. А. Лопашенко. - Москва : Волтерс Клувер, 2009. - 224 с.

5. Мальцев, В. В. Курс российского уголовного права. Общая часть. Т. II : Уголовный закон : научное исследование / В. В. Мальцев. - Москва : Юрлитинформ, 2016. - 532 с.

6. Понятовская, Т. Г. Концептуальные основы системы понятий и институтов уголовного и уголовно-процессуального права / Т. Г. Понятовская. - Ижевск : Издво Удмуртского ун-та, 1996. - 231 с.

7. Пудовочкин, Ю. Е. Учение об основах уголовного права Ю. Е. Пудовочкин. - Москва : Юрлитинформ, 2012. - 240 с.

8. Тенчов, Э. С. О принципах и основаниях закрепления в законе системы уголовно-правовых институтов // Направления уголовной политики в борьбе с преступностью: межвуз. сб. науч. тр. - Свердловск : Изд-во Свердл. юрид. ин-та, 1986. - С. 22-27.

9. Филимонов, В. Д. Охранительная функция уголовного права / В. Д. Филимонов. - Санкт-Петербург : Юридический Центр Пресс, 2003. - 198 с. 


\section{Информация об авторе}

Р. Г. Асланян - кандидат юридических наук, доцент кафедры уголовного права и криминологии Кубанского государственного университета.

\section{References}

1. Babaev M. M., Pudovochkin Yu. E. "Mertvye" normy v Ugolovnom kodekse: problemy i resheniya ["Dead" norms in the Criminal Code: problems and solutions]. Ugolovnoe parvo, 2010, no. 6, pp. 4-10.

2. Zhuk M. S. Instituty rossiiskogo ugolovnogo prava: ponyatie, sistema i perspektivy razvitiya [Institutes of Russian criminal law: concept, system and development prospects]. Dis. Dr. (Legal Sci.). Krasnodar, 2013. 380 p.

3. Kuznetsova N. F., Tyazhkova I. M. (eds.). Kurs ugolovnogo prava. V 5 t. T. 1. Uchenie o prestuplenii [Course in criminal law. In 5 volumes. Vol. 1. The doctrine of crime]. Moscow: Zertsalo-M Publ., 2002. 624 p.

4. Lopashenko N. A. Vvedenie v ugolovnoe pravo: uchebnoe posobie [Introduction to criminal law: textbook]. Moscow: Walters Kluver, 2009. 224 p.

5. Maltsev V. V. Kurs rossiiskogo ugolovnogo prava. Obshchaya chast'. T. II: Ugolovnyi zakon: nauchnoe issledovanie [Course of Russian criminal law. A common part. Vol. II: Criminal law: scientific research]. Moscow: Yurlitinform Publ., 2016. 532 p.

6. Ponyatovskaya T. G. Kontseptual'nye osnovy sistemy ponyatii $i$ institutov ugolovnogo i ugolovno-protsessual'nogo prava [Conceptual foundations of the system of concepts and institutions of criminal and criminal procedural law]. Izhevsk: Publishing house of Udmurt University, 1996. 231 p.

7. Pudovochkin Yu. E. Uchenie ob osnovakh ugolovnogo prava [Teaching about the foundations of criminal law]. Moscow: Yurlitinform Publ., 2012. 240 p.

8. Tenchov E. S. O printsipakh i osnovaniyakh zakrepleniya v zakone sistemy ugolovno-pravovykh institutov [On the principles and grounds of consolidation in the law of the system of criminal legal institutions]. In: Napravleniya ugolovnoi politiki v bor'be s prestupnost'yu [Directions of criminal policy in the fight against crime: interuniversity]. Sverdlovsk: Publishing house of Sverdl. jurid. Institute, 1986, pp. 22-27.

9. Filimonov V. D. Okhranitel'naya funktsiya ugolovnogo prava [Protective function of criminal law]. St. Petersburg: Yuridicheskii Tsentr Press Publ., 2003. 198 p.

\section{Information about the author}

R. G. Aslanyan - Candidate of Law, Associate Professor of the Department of Criminal Law and Criminology of Kuban State University. 